\title{
Erratum to: Decrease in circulating endothelial progenitor cells in treated glioma patients
}

\author{
Elena Corsini $\cdot$ Emilio Ciusani $\cdot$ Paola Gaviani $\cdot$ \\ Antonio Silvani - Alessandra Canazza - Gaetano Bernardi • \\ Chiara Calatozzolo $\cdot$ Francesco DiMeco $\cdot$ Andrea Salmaggi
}

Published online: 23 March 2012

(C) Springer Science+Business Media, LLC. 2012

Erratum to: J Neurooncol

DOI 10.1007/s11060-012-0805-8

The eighth author's family name was incorrectly captured in the original publication. It is correct in this erratum.

The online version of the original article can be found under doi:10.1007/s11060-012-0805-8.

E. Corsini - E. Ciusani - A. Canazza - G. Bernardi

Laboratory of Clinical Pathology and Medical Genetics,

Fondazione IRCCS Istituto Neurologico "C. Besta",

Via Celoria 11, 20133 Milan, MI, Italy

P. Gaviani · A. Silvani - C. Calatozzolo · A. Salmaggi ( $ه)$

Department of Neurooncology, Fondazione IRCCS Istituto

Neurologico "C. Besta", Via Celoria 11, 20133 Milan,

MI, Italy

e-mail: salmaggi@istituto-besta.it

Present Address:

C. Calatozzolo

Department of Neuropathology, Fondazione IRCCS Istituto

Neurologico "C. Besta", Via Celoria 11, 20133 Milan,

MI, Italy

F. DiMeco

Department of Neurosurgery, Fondazione IRCCS Istituto

Neurologico "C. Besta", Via Celoria 11, 20133 Milan,

MI, Italy

F. DiMeco

Department of Neurological Surgery, Johns Hopkins University,

Baltimore, MD, USA 